\title{
Assessment of non-steroidal anti-inflammatory and analgesic pharmaceuticals in seawaters of North of Portugal: Occurrence and environmental risk
}

AleksandarLolić,PaulaPaíga,LúciaH.M.L.M.Santos,SandraRamos,

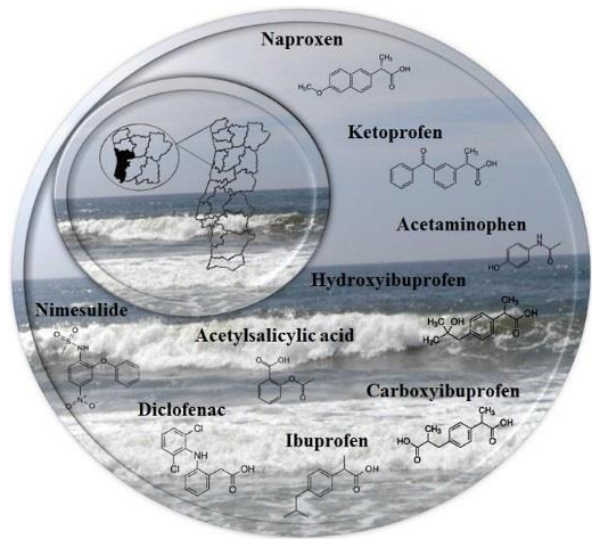

ABSTRACT

The occurrence of seven pharmaceuticals and two metabolites belonging to non-steroidal anti-inflammatorydrugs and analgesics therapeutic classes was studied in seawaters. A total of 101 samples covering fourteen beaches and five cities were evaluated in order to assess the spatial distribution of pharmaceuticals among north Portuguese coast. Seawaters were selected in order to embrace different bathing water quality (excellent, good and sufficient). Acetaminophen, ketoprofen and the metabolite hydroxyibuprofen were detected in all the seawater samples at maximum concentrations of $584,89.7$ and $287 \mathrm{ng} \mathrm{L}^{-1}$, respectively. Carboxyibuprofen had

the highest seawater concentration (1227 $\mathrm{ng} \mathrm{L}^{-1}$ ). The temporal distribution of the selected pharmaceuticalsduring the bathing season showed that, in general, higher concentrations were detected in August and Septem- ber. The environmental risk posed by the pharmaceuticals detected in seawaters towards different trophic levels (fish, daphnids and algae) was also assessed. Only diclofenac showed hazard quotients above one for fish, representing a potential risk for aquatic organisms. These results were observed in seawaters classified as excellent bathing water. Additional data is needed in order to support the identification and prioritization of risks posed by pharmaceuticals in marine environment.

Keywords:

Seawater, North of Portugal, Non-steroidal anti-inflammatory drugsAnalgesics 



\section{Introduction}

In the last few years, a special attention has been given to the assess- ment of the presence of emerging pollutants in natural waters and their effects on ecosystems. As the analytical capacity has improved in order to allow the quantification of very low concentrations (e.g. in the $\mathrm{n} \mathrm{L}^{-1}$ range) with the high degree of certainty given by the use of tandem mass spectrometry, scientists have been able to quantify these xenobi- otics in the aquatic systems (surface waters, ground waters, treated and untreated wastewaters and even tap waters) (Loos et al., 2010,

2013a).

Pharmaceuticals play an important role in assuring populations' health. However their use is not exempt from negative effects whose importance just more recently has been recognized. Indeed, every day tons of these compounds are loaded in the sewage systems and reach wastewater treatment plants (WWTPs). These have been mainly de- signed to remove suspended solids and organic loadings and their effect on the removal of micropollutants may be, in some cases, negligible. In fact, the removal efficiency of pharmaceuticals in WWTPs have been studied and a very wide range of values is observed, from compounds which pass these plants almost intact and others presenting a removal efficiency close to $100 \%$ (Kunkel and Radke, 2012). Their incomplete re- moval makes that there is a continuous discharge of pharmaceuticals into the environment, which may result in a chronic exposure of aquatic organisms to these compounds and/or their bioactive metabolites and transformation products. These products have shown, in some cases, quite similar toxicological consequences in aquatic environment.

Although the present knowledge in the occurrence and behaviour of pharmaceuticals in surface waters is well documented (e.g. Gros et al.,
2006, 2012; Paíga et al., 2013; Rabiet et al., 2006), such knowledge in seawaters is still very limited and recent.

The presence of pharmaceuticals in seawaters has been evaluated in different geographical areas, namely in the North Sea (Weigel et al., 2002), Mediterranean Sea (Gros et al., 2012; Rodriguez-Navas et al., 2013; Togola and Budzinski, 2008), Adriatic Sea (Loos et al., 2013b) and in the Pacific (VidalDorsch et al., 2012) and Indian Oceans (Fang et al., 2012; Wu et al., 2010). Several therapeutic groups were studied, including, for example, non-steroidal anti-inflammatory drugs (NSAIDs) (Gros et al., 2012; Wille et al., 2010), analgesics (Gros et al., 2012; Nödler et al., 2010), antibiotics (Nebot et al., 2007; Wille et al., 2010), $\beta$ - blockers (Gros et al., 2012; Wille et al., 2010), lipid regulators (Fang et al., 2012; Gros et al., 2012) and psychiatric drugs (Gros et al., 2012; Wille et al., 2010). Diclofenac (Rodriguez-Navas et al., 2013), ibuprofen (Loos et al., 2013b), naproxen (Vidal-Dorsch et al., 2012), ketoprofen (Gros et al., 2012), salicylic acid (Wille et al., 2010), acetaminophen (Gros et al., 2012) and codeine (Gros et al., 2012) are among the most de-tected NSAIDs/analgesics in seawaters of the North, Mediterranean and Adriatic Seas and even in the Pacific and Indian Oceans at levels up to

few hundred $\mathrm{ng} \mathrm{L}^{-1}$. Some examples of levels of NSAIDs/analgesics detected in seawaters are present in Table 1.

Recently, European Union established regulatory guidance to as- sess the presence of pharmaceuticals in the aquatic environment (Directive 2013/39/EU amending Directives 2000/60/EC and 2008/105/EC) (European Comission, 2013) as regards priority substances in the field of water policy. A watch list of pharmaceuticals including the sex hormones 17alphaethinylestradiol and 17beta-estradiol, and the NSAID diclofenac was created and is being updated with data gath- ered among the European Union countries. Regarding marine waters,

Table 1

Examples of concentrations of NSAIDS/analgesics found in seawaters.

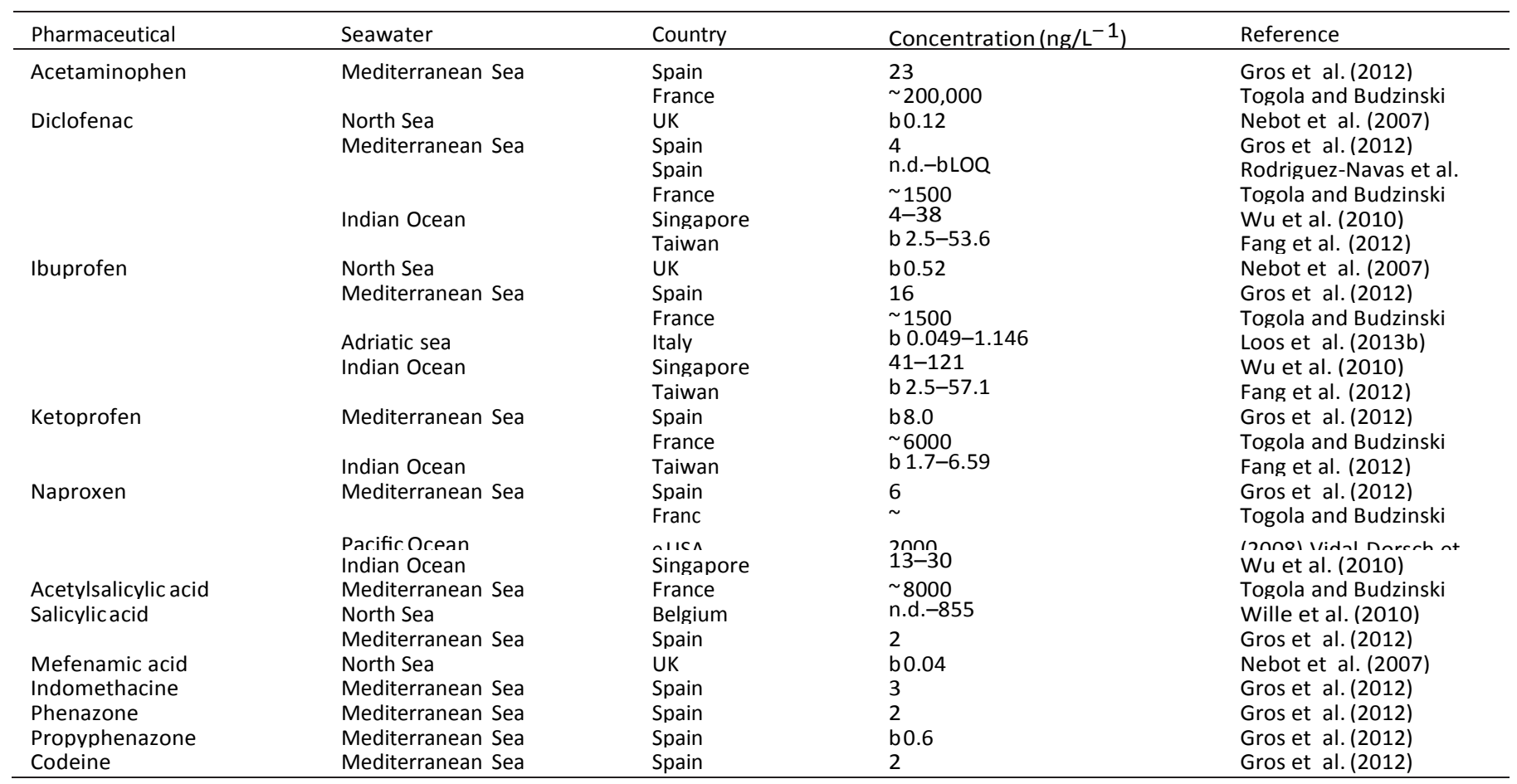


monitoring programmes for continuous evaluation of their environ- mental status should be established according to the Marine Strategy Framework Directive (European Comission, 2008), including the evalu- ation of the impact of hazardous substances as pharmaceuticals.

Coastal areas represent a major asset due to the economic activities that may take place, including tourism, commercial ports and harbours and certain types of traditional fishing. Due to their location, coastal sea- waters may be more prone to present higher pharmaceutical concentra- tions than other seawater samples (Loos et al., 2013b; Wille etal., 2010). In Portugal, coastal areas are the most densely populated regions where the largest cities and the most important

industries are situated. To the best of our knowledge, the only data available about the occur- rence of pharmaceuticals in Portuguese seawaters is reported in our previous work (Paíga et al., in press).

The purpose of this work was to evaluate the occurrence of seven pharmaceuticals and two metabolites belonging to NSAIDs/analgesics group in seawaters, in a total of 101 samples, collected in the summer season of 2013 from 14 beaches. Compounds were selected based on their high consumption among Portuguese population (INFARMED, 2012) and to previous studies of our group that showed their presence in Portuguese environment, namely wastewaters (Santos et al., 2013a) and surface waters (Paíga et al., 2013), at levels that could pose a risk for aquatic organisms. Differences observed between municipalities, tem- poral variations as well as environmental risk will be discussed.

\section{Materials and methods}

\subsection{Reagents, solvents and materials}

All pharmaceutical standards were of high purity grade ( $\geq 98 \%$ ). Ibuprofen, 1-hydroxyibuprofen, carboxyibuprofen, acetaminophen, acetylsalicylic acid, naproxen, nimesulide, ketoprofen and diclofenac were purchased from Sigma-Aldrich (Spain). Diclofenac was pur- chased in the form of sodium salt. The isotopically labelled com- pound ibuprofen-d3 used as internal standard was also purchased from Sigma-Aldrich.

Both individual stock standard and isotopically labelled internal standard solutions (at a concentration of $1000 \mathrm{mg} \mathrm{L}^{-1}$ ) were prepared on a weight basis in acetonitrile, except for naproxen and diclofenac, which were prepared in acetonitrile-methanol (50:50, v/v). All stock standard solutions were prepared every six months and were stored at $-20{ }^{\circ} \mathrm{C}$. Working standard solutions containing all pharmaceuticals were prepared in acetonitrile-ultrapure water $(30: 70, \mathrm{v} / \mathrm{v})$ by mixing

appropriate amounts of the stock solutions. These solutions were pre- pared before each analytical run.
Acetonitrile and methanol for LC-MS were supplied by J.T. Baker (Deventer, Netherlands), and hydrochloric acid $37 \%$ was obtained from Carlo Erba (Rodano, Italy).

Ultra-pure water (resistivity of $18.2 \mathrm{M} \Omega \cdot \mathrm{cm}$ ) was produced using a Simplicity 185 system (Millipore, Molsheim, France). All chromato- graphic solvents were filtered through a $0.22 \mu \mathrm{m}$ nylon membrane filter (Supelco, Bellefonte, PA, USA) using a vacuum pump (Dinko D-95, Barcelona, Spain) and degassed for $15 \mathrm{~min}$ in an ultrasonic bath (SonorexDigital 10P, Bandelin DK255P, Germany).

Solid phase extraction (SPE) was performed using Strata-X car- tridges (200 mg, $3 \mathrm{~mL}$ ) from Phenomenex (USA).

\subsection{Sampling sites and sample collection}

Seawater samples were collected in the Atlantic Ocean along the North Portuguese coast, covering fourteen beaches from five cities and surrounding area (Vila do Conde, Matosinhos, Porto, Vila Nova de Gaia and Espinho) (Fig. 1 and Table S1, Supporting material). The area of study is densely populated and embraces coastal waters that receive water from different river basins, which have a strong impact of anthro- pogenic activities, as WWTP discharges, untreated effluents, and agricul- tural runoffs. Therefore, different organic pollutants have been detected in Ave (Rocha et al., 2013), Leça (Rocha et al., 2012) and Douro rivers (Ribeiro et al., 2009), including pharmaceuticals (Gonçalves et al., 2013; Madureira et al., 2010; Paíga et al., 2013).

In Vila do Conde two beaches were sampled (Frente Urbana and Mindelo), being the former located on the mouth of Ave river. This area is impacted by the discharges of a WWTP, which serves 258,000 pop- ulation equivalents (p.e.) and has primary, secondary and tertiary treat- ments. In Matosinhos four beaches (Angeiras Norte, Azul (Conchinha), Leça da Palmeira and Matosinhos) were studied. Leça river flows into the Atlantic Ocean in the area of Leça da Palmeira and Matosinhos beaches. In this area the second biggest artificial Portuguese harbour (Leixões harbour) and a refinery of petroleum derivates are also located.Additionally there are four WWTPs with different capacities (from 17,000 to 80,000 p.e.) that discharge their effluents into rivers and streams that flow into the Atlantic Ocean, and even directly into seawater, in Matosinhos area. All these WWTPs have primary and secondary treat- ments by activated sludge. Porto is the second most populous city of Portugal and two beaches were chosen in its coastal area (Castelo do Queijo and Foz). Foz beach is located in the mouth of Douro river, a river basin which receives discharges from several WWTPs either by direct discharge ( 2 WWTPs) or through its tributaries (4 WWTPs). Those WWTPs vary in their capacity (from 45,000 to 200,000 p.e.) as well as in the treatments applied (primary, secondary and, in some cases, even

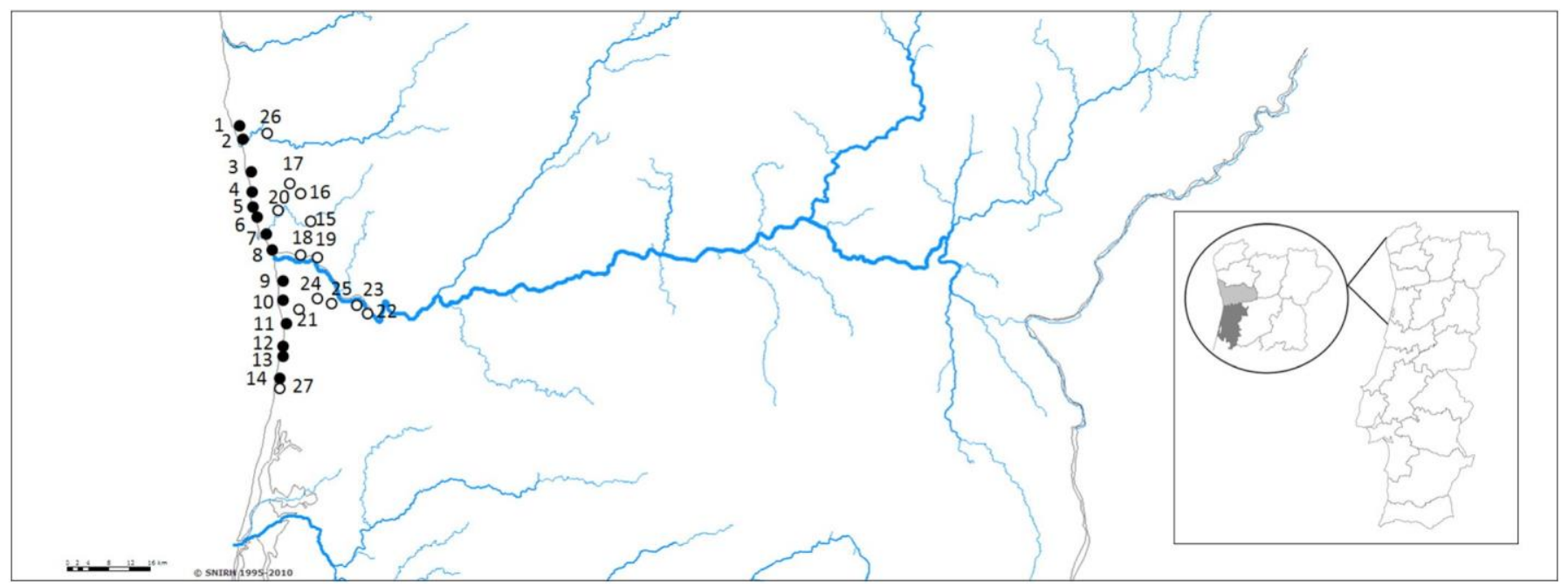

Fig. 1. Seawater sampling points and wastewater treatment plants (WWTPs) in the study area. 1 to 14 - seawater samples; 15 to $27-$ WWTPs. 
tertiary treatments by sand filtration and UV disinfection). Three beaches of Vila Nova de Gaia area, namely Lavadores, Miramar and São Félix da Marinha were also sampled. The first one is located near the mouth of the Douro river while the others receive small streams. It is in this area that is located a large WWTP that serves 300,000 p.e. and has primary, secondary and tertiary treatment that discharges its effluents directly into the Atlantic Ocean at $30 \mathrm{~m}$ of depth. Finally, three beaches of Espinho area were also studied (Seca, Frente azul and EspinhoBaía). This coastal area also receives small streams of surrounding environment and there is a WWTP, which discharges its effluents directly into the Atlantic Ocean in the vicinity of the studied seawaters. It serves 100,000 p.e. and has primary and secondary treatments.

Sampling locations were chosen taking into account the bathing water quality, therefore beaches with bathing water quality classified as excellent, good and sufficient, according to European regulation (European Comission, 2006), were taken into consideration, namely seven beaches of excellent, four of good, and three of sufficient. Howev- er it should be highlighted that bathing water quality classification only takes into account microbiological parameters (European Comission, 2006). Detailed information on sampling sites and their geographical lo- cation (GPS) are given in Tables S1 and S2 (Supporting material). Sam- pling campaigns took place during the bathing season from June to September 2013. Sampling frequency was determined taking into ac- count the bathing water quality, thus for excellent bathing waters, sam- ples were only collected once a month; for good every two weeks; andfor sufficient bathing waters every week. A total of 101 samples were collected for further analysis. $1.5 \mathrm{~L}$ of seawater was collected in bottles previously rinsed with ultra-pure water as grab samples and at a depth of at least $1 \mathrm{~m}$. Samples were kept at 4 ${ }^{\circ} \mathrm{C}$ during the transport to the laboratory. Upon reception, samples were vacuum filtered through $1.2 \mu \mathrm{m}$ glass microfiber filters (GF/C, Whatman, UK), followed

by $0.22 \mu \mathrm{m}$ nylon membrane filters and stored at $-20^{\circ} \mathrm{C}$, until extrac-

tion. The detected concentrations of pharmaceuticals correspond to their dissolved fraction, since suspended solids were removed during sample preparation.

Data relative to seawater temperature and $\mathrm{pH}$, environmental temperature, and microbiological determinations of Escherichia coli and Enterococcus were given by the Portuguese Environment Agency(APA, 2013).

\subsection{Analytical method}

Sample preparation and analysis were made according to the proce- dure described in (Paíga et al., in press). Briefly, after filtration, sample's $\mathrm{pH}$ was adjusted to 2.0 with concentrated hydrochloric acid and $500 \mathrm{~mL}$ of seawater was loaded onto Strata- $X$ cartridges $(200 \mathrm{mg}, 3 \mathrm{~mL}$ ) previ- ously conditioned with $5 \mathrm{~mL}$ of methanol followed by $5 \mathrm{~mL}$ of ultra- pure water and $5 \mathrm{~mL}$ of ultra-pure water $\mathrm{pH} 2$. Afterwards the cartridge was rinsed with $5 \mathrm{~mL}$ of ultra-pure water and then dried under vacuum for $1 \mathrm{~h}$ to remove the excess water. Elution was performed with 2

$\times 5 \mathrm{~mL}$ of methanol. The extract was evaporated until dryness under a gentle stream of nitrogen and reconstituted with $1 \mathrm{~mL}$ of acetonitrile-

ultra-pure water $(30: 70, \mathrm{v} / \mathrm{v})$. Finally, $10 \mu \mathrm{L}$ of an ibuprofen-d3 standard solution was added to obtain a final concentration of $50 \mathrm{mg} \mathrm{L}^{-1}$ in the ex-tract as internal standard.

Instrumental analysis was performed on a Shimadzu Nexera UHPLC system (Shimadzu Corporation, Kyoto, Japan), equipped with two solvent delivery modules, a column oven, an autosampler, and coupledwith a Shimadzu LCMS8030 triple quadrupole mass spectrometer (Shimadzu Corporation, Kyoto, Japan). Lab Solutions software (Shimadzu Corporation, Kyoto, Japan) was used for control and data processing. Chromatographic separation was achieved in a Kinetex $\mathrm{C} 18$ column $(2.6$

$\times 150 \mathrm{~mm}$ i.d., $1.7 \mu \mathrm{m}$ particle size) from Phenomenex (USA), using ultra-pure water as solvent $A$ and acetonitrile as solvent $B$ at a flow rate of $0.22 \mathrm{~mL} \mathrm{~min}^{-1}$. The injection volume was $5 \mu \mathrm{L}$ and column oven was set at $30{ }^{\circ} \mathrm{C}$. The autosampler was operated at $4{ }^{\circ} \mathrm{C}$. Pharmaceuticals were analyzed in the negative ESI mode.

Quantification of analytes was performed in multiple reaction mon- itoring mode (MRM) and two transitions between the precursor ion and the most abundant fragment ions were monitored for each com- pound, as described in detail elsewhere (Paíga et al., in press). The most intense was used as quantifier and the second one as qualifier. In the case of acetaminophen, hydroxyibuprofen, ketoprofen, ibuprofen and ibuprofen-d3 only one transition could be recorded due to their poor fragmentation. A dwell time of $25 \mathrm{~ms}$ was used for all compounds. Detailed information of the optimized mass spectrometer parameters is shown in Table S3 (Supporting material).

\subsection{Statistical analysis}

Prior to multivariate data analysis, univariate descriptive statistics analysis was made (minimum, maximum, mean, median, standard de- viation and frequency of detection) for the different measured variables (pharmaceutical's concentration, seawater temperature, seawater $\mathrm{pH}$, environmental temperature, and microbiological determinations of

E. coli and Enterococcus). Pairwise correlation between two variables was also investigated in order to evaluate if there are correlation be- tween the different studied variables.

After determining the frequency of detection for the studied pharmaceuticals, only the compounds that were detected in more than $10 \%$ of seawater samples were considered for further multivariate data analysis (Navarro et al., 2010). Therefore, microbiological parameters (E. coli and Enterococcus) and the concentration of six pharmaceuticals and one metabolite were considered.

For multivariate data analysis, special attention has to be taken into account for values below the detection limit and for the presence of missing values. For the former, values were assumed to be equal to half of the limit of detection (Navarro et al., 2010). Limits of detection are present in Table 2. While the missing values were estimated using multiple imputation by chained equations (Azur et al., 2011).

Principal Component Analysis (PCA) was set with the variables acetaminophen, diclofenac, hydroxyibuprofen, ibuprofen, naproxen, and ketoprofen (using the concentrations found in seawater), E. coli and Enterococcus (expressed in colony forming units (CFU) per $100 \mathrm{~mL}$ ). Components with eigenvalues higher than 1 were retained for further analysis.

Statistical analysis was performed using SPSS software, version 20.0 (SPSS Inc., Chicago, Illinois). A two-tailed p value b 0.05 was considered to indicate statistical significance.

\subsection{Environmental risk assessment}

Environmental risk assessment of studied pharmaceuticals was evaluated regarding their hazard quotient $(\mathrm{HQ})$, using three different trophic levels representative of the aquatic ecosystem (algae, daphnids and fish). HQs were calculated according to EU guidelines (European Comission, 2003) as the quotient between the measured environmental concentration (MEC) and predicted no-effect concentration (PNEC), where the maximum individual concentration of each pharmaceutical found in seawater samples from the different studied beaches was used as MEC. PNEC values were estimated using the lowest acute eco- toxicological data reported in literature (EC50 or LC50) for short term standard toxicity studies using species from three different trophic levels (fish, Daphnia and algae) and applying an assessment factor (usually 1000) (European Comission, 2003), in order to set up a worst case scenario. Detailed ecotoxicological data used for each pharmaceutical is summarized in the Supporting material (Table S4). If HQ is equal or above 1 there is a potential environmental risk situation, whereas when lower than 1 , no risk is expected (Straub, 2002). 
Table 2

Summary data for the different parameters evaluated in Portuguese seawaters.

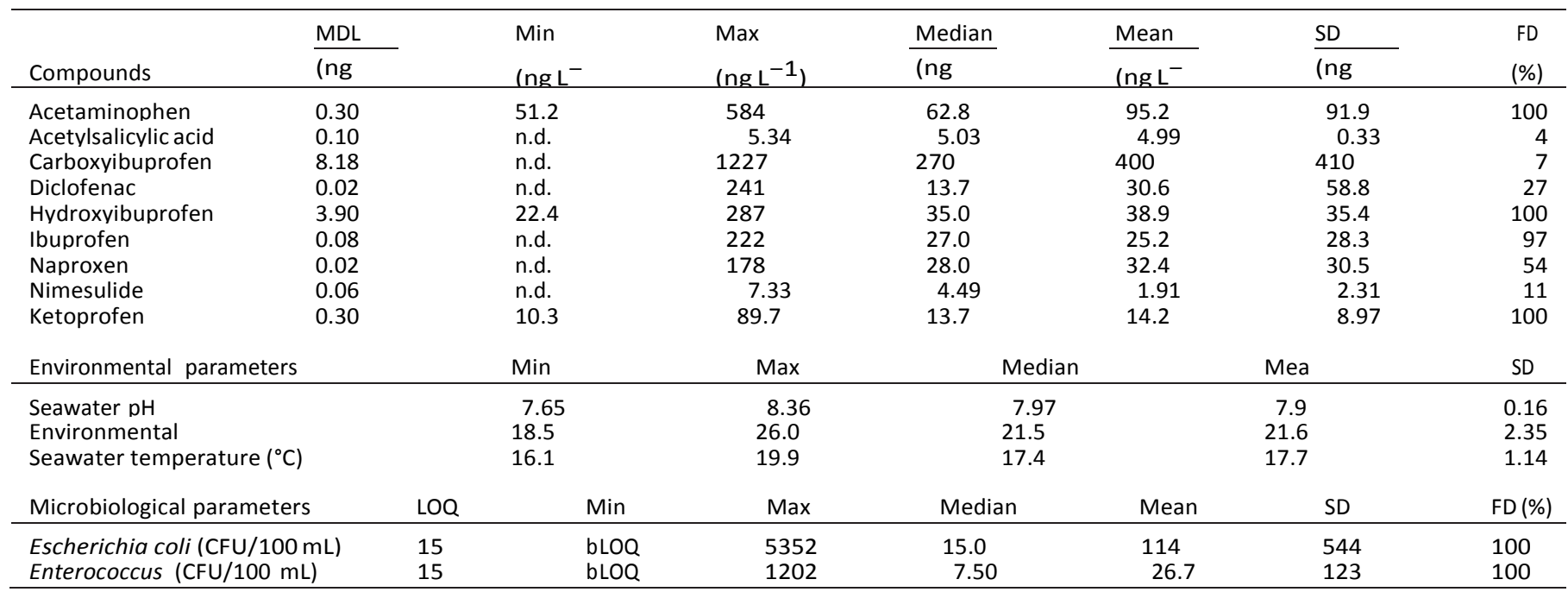

$\mathrm{MDL}$ - method detection limit; Min - minimum concentration; Max - maximum concentration;SD — standard deviation; FD — frequency of detection; LOQ

- limit of quantification; n.d. - not detected.

3. Results and discussion

3.1. Occurrence of pharmaceuticals in Portuguese seawaters: geographical and temporal variation

Table 2 summarizes the results obtained for the occurrence of the se- lected pharmaceuticals in seawater. Three out of nine pharmaceuticals were detected in all the samples, namely acetaminophen, ketoprofen and the metabolite hydroxyibuprofen. Maximum concentrations of pharmaceuticals ranged between $5.34 \mathrm{ng} \mathrm{L}^{-1}$ and $1227 \mathrm{ng} \mathrm{L}^{-1}$, for acetylsalicylic acid and carboxyibuprofen, respectively. However, only in the coastal waters of Matosinhosand Espinhoit waspossibletodetect allthestudied pharmaceuticalsat leastin one sample.Among the differ- ent studied cities, concentration ranges were between $1.76 \mathrm{ng} \mathrm{L^{- }} 1$ (nimesulide) and $76.9 \mathrm{ng} \mathrm{L^{- }} 1$ (acetaminophen) for Vila do Conde seawaters, between $2.49 \mathrm{ng} \mathrm{L^{-1 }}$ (nimesulide) and $600 \mathrm{ng} \mathrm{L}^{-1}$ (carboxyibuprofen) for Matosinhos seawaters, between $5.24 \mathrm{ng} \mathrm{L^{- }} 1$ (nimesulide) and $1227 \mathrm{ng} \mathrm{L}^{-1}$ (carboxyibuprofen) for Porto seawaters, between $0.69 \mathrm{ng} \mathrm{L}^{-1}$ (nimesulide) and $241 \mathrm{ng} \mathrm{L}^{-1}$ (diclofenac) for Vila Nova de Gaia seawaters, and between 5.12 $n g ~^{-1}$ (acetylsalicylic acid) and $236 \mathrm{ng} \mathrm{L}^{-1}$ (carboxyibuprofen) for Espinho seawaters (Fig. 2). Re- garding the distribution of acetaminophen concentrations, according to the results of the post-hoc tests, Porto is significantly different from Vila Nova de Gaia $(p=0.022)$ and Espinho $(p=0.014)$ (Fig. 2$)$ when a $p \leq 0.05$ wasconsidered.

In general, the highest concentrations of pharmaceuticals were found in seawaters from Porto coastal area. Compounds like acetamin- ophen, naproxen, ibuprofen and its two metabolites (carboxyibuprofen and hydroxyibuprofen) recorded its highest concentrations in seawater samples from Castelo do Queijo beach, reaching levels of few micro- grams per litre (Tables S5-S9, Supporting material). These results may be due to the negative pressures of different anthropogenic activities in this beach, given that WWTPs located in the surrounding area discharge their effluents in this point and this beach is also impacted by Leixões harbour activities. The discharge of untreated effluents may also occur. Castelo do Queijo beach is also located in the vicinity of Leça and Douro river mouths, where the presence of NSAIDs and an- algesics had been reported (Gonçalves et al., 2013; Paíga et al., 2013;

Santos et al., 2013b). Indeed, in a previous work ibuprofen was detected in Douro and Leça river mouths at levels up to $232 \mathrm{ng} \mathrm{L}^{-1}$ and $256 \mathrm{ng} \mathrm{L}^{-1}$, respectively (Paíga et al., 2013). On the other hand, the highest concentrations of nimesulide and ketoprofen were detected in
Espinho coastal area (Fig. 2), being the former found in Seca beach while the latter occurred in Espinho-Baía beach (Table S9, Supporting material). It is worth noting that the highest level of ketoprofen $\left(89.7 \mathrm{ng} \mathrm{L}^{-1}\right.$ ) was detected in seawater classified as excellent for bath- ing water quality. The occurrence of pharmaceuticals in Espinho coastal waters can be explained by the presence of a WWTP in the area of study, which serves 100,000 p.e. and discharges its effluents directly to the Atlantic Ocean. For diclofenac and acetylsalicylic acid, the highest con- centrations were found in Vila Nova de Gaia coastal area, in Lavadores beach and São Félix da Marinha beach, respectively (Fig. 2 and Table S8, Supporting material). As it happens for ketoprofen, the highest concentra-

tion of diclofenac was also detected in a beach classified as excellent for bathing water quality. However, Lavadores beach is located in the vicinity of Douro river mouth and, therefore, being impacted by the pollutants present herein, namely pharmaceuticals. Ralo stream is also a tributary for this beach that might be pointed out as a possible source of contami-nation. Relative to São Félix da Marinha beach, in its surrounding area a WWTP that serves 300,000 p.e. is located and discharges its effluents di- rectly into the Atlantic Ocean, which may contribute to the entrance of pharmaceuticals into seawaters. Another possible source of contamina- tion for this beach is its tributary Prego stream.

Data on the presence of pharmaceuticals in seawaters is still sparse and there are only a few studies focusing in this topic. Lower concentra- tions of NSAIDs were reported in Mediterranean Sea (Spain) (Gros et al., 2012; Rodriguez-Navas et al., 2013), in Singapore coastal waters (Bayen et al., 2013) and in the Pacific Ocean (California, USA) (Bay et al., 2012; Vidal-Dorsch et al., 2012), being usually the concentrations detected one order of magnitude lower than those reported in this study. Ibupro- fen was also detected in Adriatic Sea at levels up to $1.146 \mathrm{ng}$ $\mathrm{L}^{-1}$ (Loos et al., 2013b). On the other hand, Wu et al. (2010) reported similar find- ings for naproxen and diclofenac in Marine Bay (Singapore) (Wu et al., 2010). In Taiwan coastal waters, the concentrations of diclofenac and ibuprofen were also in the same order of magnitude of those reported herein, though ketoprofen was detected at lower levels, not exceeding $7 \mathrm{ng} \mathrm{L}^{-1}$ (Fang et al., 2012). Nevertheless, Nödler et al. (2010) were not able to detect diclofenac, ibuprofen, naproxen and acetaminophen in the Baltic Sea (German coastal area) (Nödler et al., 2010).

Albeit the high consumption of acetylsalicylic acid among Portu- guese population (INFARMED, 2012), it was only detected in $4 \%$ of the seawater samples, at a maximum concentration of $5.34 \mathrm{ng} \mathrm{L}^{-1}$ (Table 2). These low levels might be justified by its ready biodegrada- tion in the aquatic environment, forming salicylic acid, a more active 


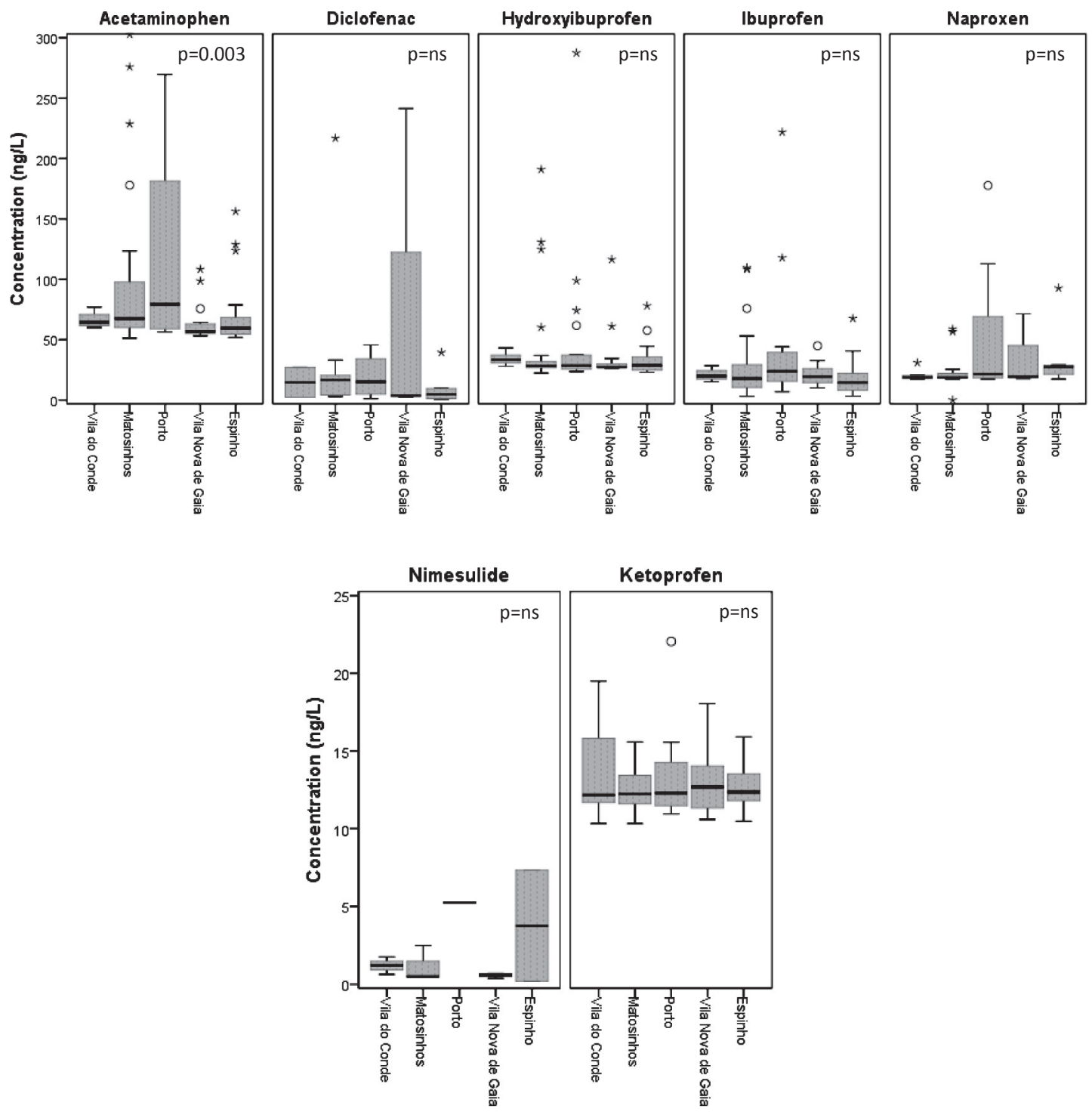

Fig. 2. Box plots indicating the distribution of some pharmaceuticals concentration, expressed in $\mathrm{ng}^{-1}$, among the studied cities. Please note that the scale for the $y$-axis (concentration in $\mathrm{ng} \mathrm{L}^{-1}$ ) changes between boxes. $0-$ outliervalues; $\star$ - extreme outliervalues. Comparisons between cities were assessed with the Kruskal-Wallis test followed by post hoc tests. ns not significant.

metabolite (Cleuvers, 2004; Rabiet et al., 2006) together with its high removal efficiency in WWTPs that may range from 80 to $98 \%$ (Ziylan and Ince, 2011). No data on the occurrence of acetylsalicylic acid in sea- waters is available in literature, though the presence of its main metab- olite salicylic acid had been reported in the Belgian coastal area (North Sea) (Wille et al., 2010) and in the Mediterranean Sea (Spain) (Gros et al., 2012), at levels up to $660 \mathrm{ng} \mathrm{L}^{-1}$.

On the other hand, the ibuprofen metabolite carboxyibuprofen showed the highest concentration detected in Portuguese seawaters (up to $1227 \mathrm{ng}$ $\mathrm{L}^{-1}$ ) (Table 2). However, in spite of its high concentra-tion, carboxyibuprofen was only detected in $7 \%$ of the seawater samples, contrarily to what happens with ibuprofen and its metabolite hydroxyibuprofen that have a frequency of detection of 97 and $100 \%$, re- spectively, with their concentrations reaching 222 $\mathrm{ng} \mathrm{L^{-1 }}$ for ibuprofen and $287 \mathrm{ng} \mathrm{L^{-1 }}$ for hydroxyibuprofen. Although when ibuprofen and its two metabolites were detected in the same sample, carboxyibuprofen always showed the highest concentration, as was expected since it is the human metabolite of ibuprofen with highest percentage of excre- tion (43\%) (Farré et al., 2008). The same pattern was observed by Weigel et al. (2004) in seawater samples from the Norwegian coast (Tromsø) (Weigel et al., 2004). Nevertheless, hydroxyibuprofen showed to be more stable than ibuprofen and carboxyibuprofen, which is in agreement with data from literature that indicates hydroxyibuprofen as the less biodegradable compound (Ferrando-Climent et al., 2012; Winkleret al., 2001). Due to its high biodegradability in the environment, the pres- ence of carboxyibuprofen in seawaters might be attributed to discharges of WWTP effluents or even of untreated effluents. Carboxyibuprofen was detected in seawaters from four beaches, being two of them classified as excellent for bathing water quality, namely Foz beach (Porto) and Espinho-Baía beach (Espinho), and the other two have classification of sufficient (Azul Conchinha beach (Matosinhos) and Castelo do Queijo beach (Porto)) (Tables S5-S9, Supporting material).

The temporal variation of pharmaceuticals' concentration was followed along the bathing season, from June to September 2013 (Fig. 3). Taking into account the compounds with high frequency of de- tection, it was observed that the highest concentrations were registered in August and September, with the exception of ketoprofen that showed a constant profile along the bathing season, registering a small variation in its concentration. The behaviour of ketoprofen might be justified by its difficult removal during wastewater treatment, being consistently found in surface waters (Shanmugam et al., 2014). Ketoprofen can also occur as ion at neutral or basic $\mathrm{pH}$, and therefore is not readily 


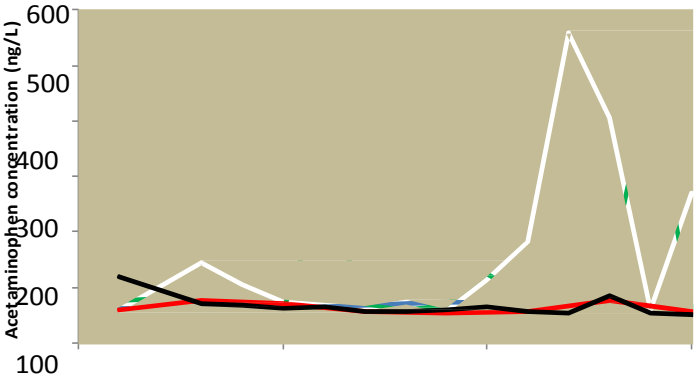

0

15

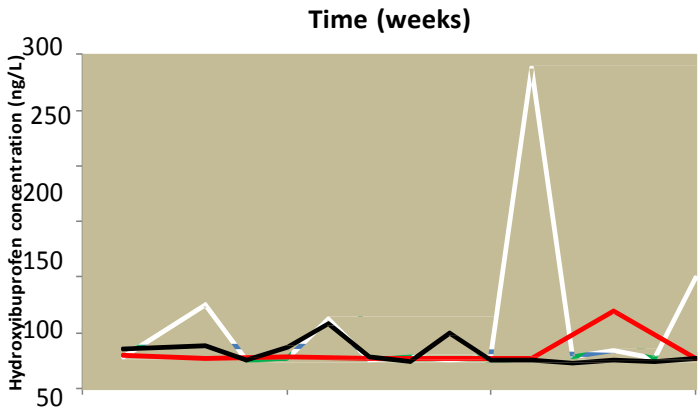

0

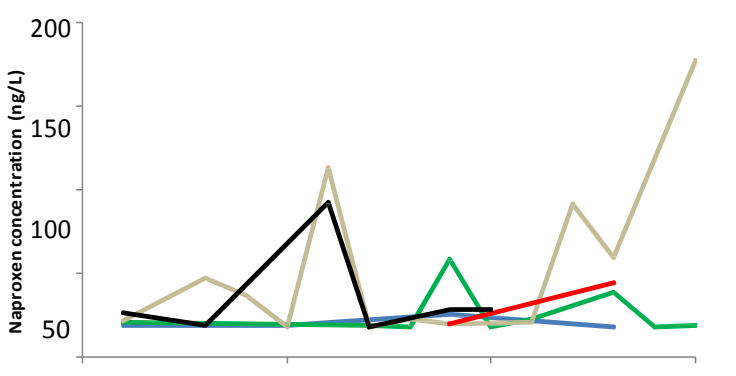

0
0

15

Time (weeks)

10

0
5
10 15

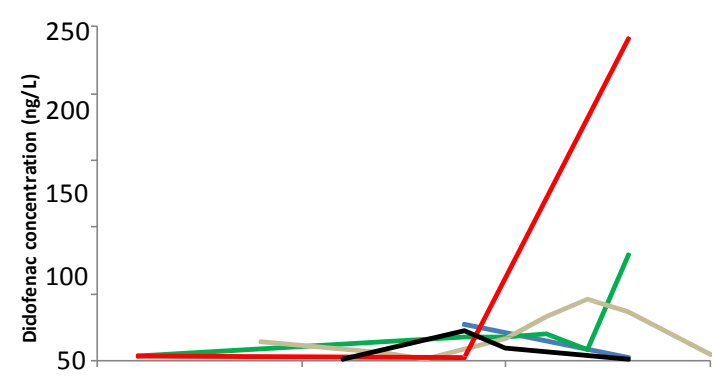

0

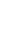

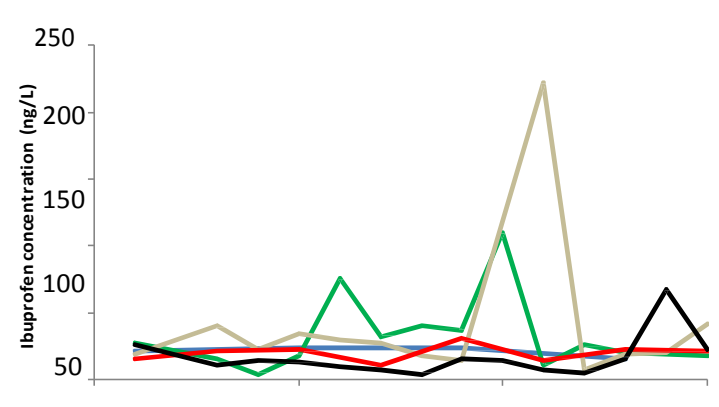

0 0 5 10 15 Time (weeks)

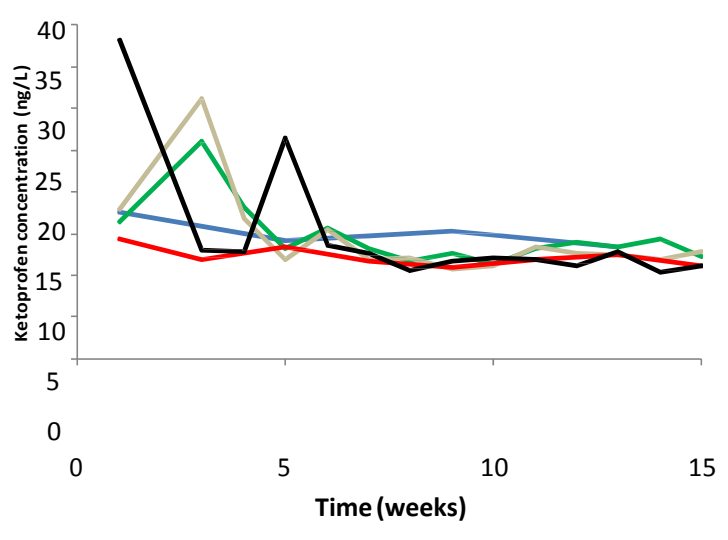

Time (weeks)

- Vila do Conde Matosinhos Porto - Vila Nova de Gara Espinho

Fig. 3. Temporal distribution of most relevant pharmaceuticals along the bathing season in the different cities.

adsorbed on particulate material, remaining in the aqueous phase (Araujo et al., 2014). On the other hand, the higher levels of pharmaceu- ticals observed in August and early September can be explained by an increase in population in the study area during these months, due to a higher level of tourists at that time, either by summer holidays or by an increment in the traffic of cruise boats in Leixões harbour (INE, 2014). Additionally, in August and September raining events are also less abundant, making that rivers and streams have a small capacity, being more negatively impacted by human activities as the discharges of WWTPs effluents, due to the dilution of pharmaceuticals in surface

Table 3

Pairwise correlation coefficients between the variables.

\begin{tabular}{lllllllllll}
\hline & ACET & DICL & HYDR & IBUP & NAPR & NIME & KETOP & pH & EMT & SWT \\
\hline ACET & 1 & & & & & & & & \\
DICL & 0.118 & 1 & & & & & & \\
HYDR & 0.221 & 0.423 & 1 & & & & & \\
IBUP & 0.111 & 0.024 & 0.682 & 1 & & & & \\
\end{tabular}




\begin{tabular}{|c|c|c|c|c|c|c|c|c|c|c|c|}
\hline NAPR & 0.486 & 0.188 & 0.292 & 0.020 & 1 & & & & & & \\
\hline NIME & 0.379 & -0.454 & -0.216 & 0.011 & -0.214 & 1 & & & & & \\
\hline KETOP & -0.026 & -0.117 & -0.015 & -0.005 & -0.045 & 0.212 & 1 & & & & \\
\hline $\mathrm{pH}$ & -0.152 & -0.161 & 0.109 & 0.082 & 0.144 & 0.140 & -0.064 & 1 & & & \\
\hline EMT & 0.295 & 0.378 & 0.144 & -0.029 & 0.103 & -0.050 & -0.061 & -0.474 & 1 & & \\
\hline SWT & -0.183 & -0.230 & -0.033 & 0.154 & -0.244 & 0.145 & -0.122 & 0.376 & -0.128 & 1 & \\
\hline EC & 0.037 & 0.526 & 0.036 & -0.015 & -0.054 & -0.226 & 0.407 & -0.029 & -0.159 & -0.151 & 1 \\
\hline ENT & 0.006 & -0.129 & -0.017 & -0.049 & -0.064 & 0.426 & 0.392 & -0.036 & -0.135 & -0.134 & 0.978 \\
\hline
\end{tabular}

Significant pairwise correlations are marked in bold (significance $5 \%$ ).

ACET - acetaminophen;DICL - Diclofenac; HYDR - hydroxyibuprofen;IBUP - ibuprofen; NAPR - naproxen;NIME - nimesulide; KETOP - ketoprofen; $\mathrm{pH}$ seawaterpH;EMT - environ- mental medium temperature; SWT — seawater temperature; EC — Escherichia coli; ENT — Enterococcus. 


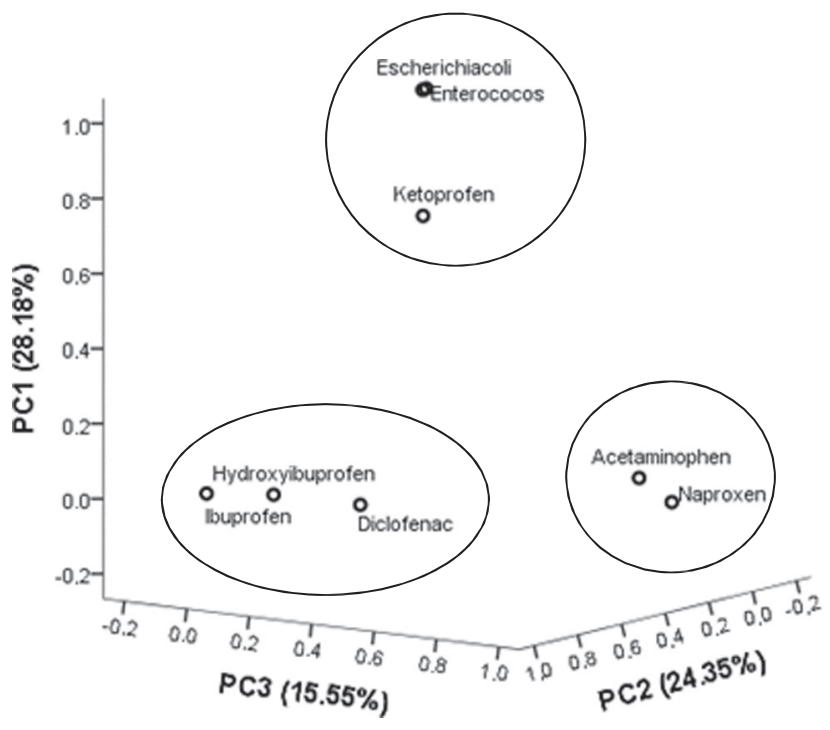

Fig. 4. Component loadings plot in rotated space.

waters being less pronounced, which can be reflected in a higher impact of anthropogenic activities intoseawaters.

\subsection{Statistical analysis}

In Table 3, pairwise correlations between the studied variables are given. As expected, there was a strong correlation between microbio- logical parameters (E. coli and Enterococcus), since both parametersare indicators of faecal contamination and of a negative impact of human activities in seawaters. Relatively to physicochemical variables, there was a negative correlation between environmental temperature and seawater $\mathrm{pH}$, while this latter parameter was positively correlated with seawater temperature. Concerning pharmaceuticals, acetamino- phen, diclofenac, ibuprofen, hydroxyibuprofen and naproxen showed correlations among each other. These suggested a possible common source of entrance into seawaters for the studied pharmaceuticals. Ad- ditionally, ibuprofen and its metabolite hydroxyibuprofen had a moder- ate correlation, what was expected due to the stability of this metabolite and its pattern of occurrence together with the parent compound (see Section 3.1.). Pharmaceuticals like diclofenac and ketoprofen also had a positive correlation with the microbiological parameters (E. coli and Enterococcus), which may suggest a common source of entrance of

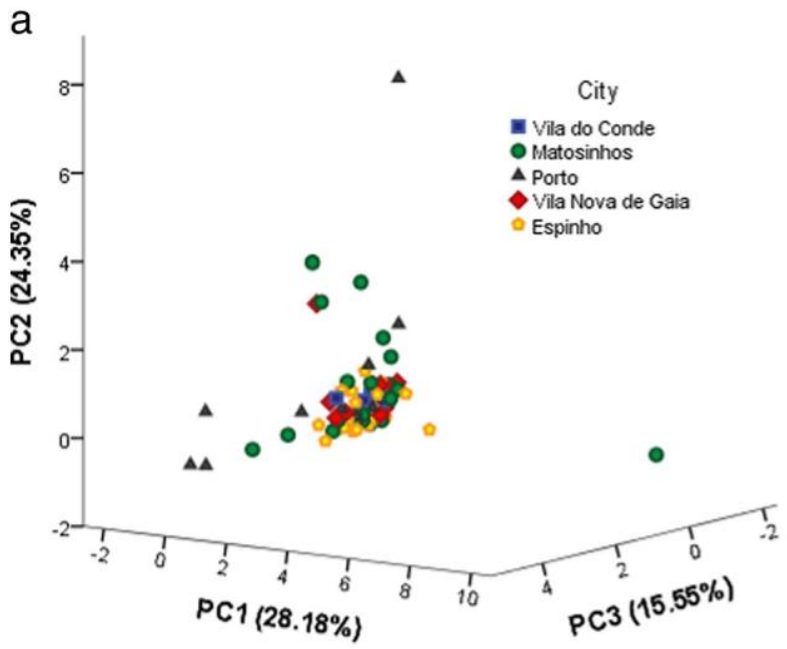

pharmaceuticals and these biomarkers of faecal contamination into sea- waters. The most probable source of contamination should be WWTP effluents and untreated effluents that are directly discharged into the environment.

To better understand the multivariate correlations among the differ- ent variables, seawater sampling locations and seawater bathing water quality, a Principal Component Analysis (PCA) was made. PCA was per- formed combining the data obtained for pharmaceuticals and the mi- crobiological parameters. The first three principal components (PCs) explained $68 \%$ of the variance and their loading plots are represented in Fig. 4 . It can be seen that the first PC had positive loadings for E. coli, Enterococcus and ketoprofen, while for the second PC contributed the compounds diclofenac, ibuprofen and hydroxyibuprofen. Finally, the pharmaceuticals acetaminophen and naproxen have high positive load- ingsin the third PC. Both microbiological parameters havehighloadings in the first PC, allowing the identification of a source contamination by WWTP effluents or untreated effluents, which are positively correlated with the concentration of ketoprofen. These results are in agreement with the correlation coefficients found for these variables (Table 3 ).

In Fig. 5, the PC1 vs. PC2 vs. PC3 score plots of data are shown. In order to better analyze the results obtained, samples were arranged ac- cording to their city of origin (Fig. 5a) and their classification of bathing water quality (Fig. 5b). From Fig. 5 a it can be seen that there is not a very clear spatial distribution of the samples by their origin. However, sam- ples from cities of Porto and Matosinhos can be gathered in a cluster, that presents high positive score values for PC2 combined with positive score values in PC3 and PC1, indicating that these sampling locations had the highest concentration of pharmaceuticals. Correlating the dif- ferent studied variables with the classification of bathing water quality (Fig. 5b), two groups were distinguished. The first cluster includes sam- ples from seawaters classified as sufficient, showing high positive score values for $\mathrm{PC} 2$ and $\mathrm{PC} 3$. This may indicate that these samples have a more pronounced impact of human activities, since they have higher concentration of pharmaceuticals. The other cluster gathers seawaters classified as excellent or good, showing also positive score values for PC2 and PC3, but not as high as in the first cluster.

\subsection{Environmental risk assessment}

Besides the quantification of emergent pollutants in the environ- ment, it is also important to evaluate potential ecological risks that they may pose to non-target organisms at environmental levels. In this way, hazard quotients (HQ) can be a useful tool, establishing the quotient between Predicted Environmental Concentration (PEC) and Predicted No-Effect Concentration (PNEC) (Ginebreda et al., 2010; b

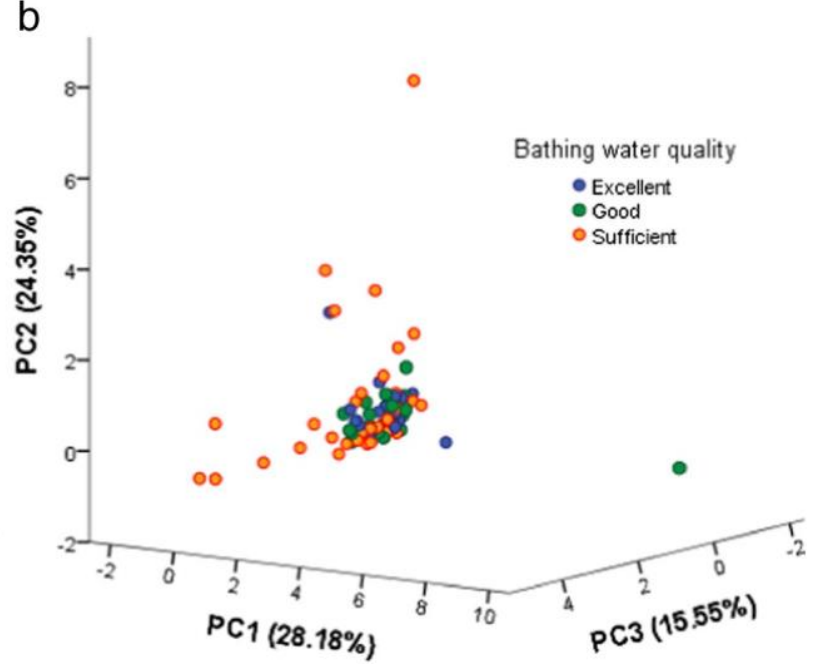

Fig. 5. Score plots from PCA. a) For the different cities; b) for bathing water quality. 
Verlicchietal.,2012). The replacementof PECvalues by Measured Envi- ronmental Concentration (MEC) allows a more realistic scenario to as- sess environmental risk posed by pollutants as pharmaceuticals.

In this work, environmental risk assessment was evaluated for three different trophic levels (algae, daphnids and fish). HQs were calculated for the seawaters collected in the different beaches using an approach of "worst case scenario", that is the highest level detected for each phar- maceutical was used as MEC. Dueto the sparse data for ecotoxicological effects in marine organisms available in literature, environmental risk assessment was evaluated considering ecotoxicological data for fresh- water organisms. Fig. 6 summarizes the HQs obtained. As can be seen, fish showed higher HQs and was the only specie that had HQs higher than one, while daphnids and algae had similar sensitivity to the detect- ed pharmaceuticals and never exceeded the threshold value of one. Diclofenac was the pharmaceutical that registered the highest HQs for fish and in two sampling points (Azul Conchinha (Matosinhos) and
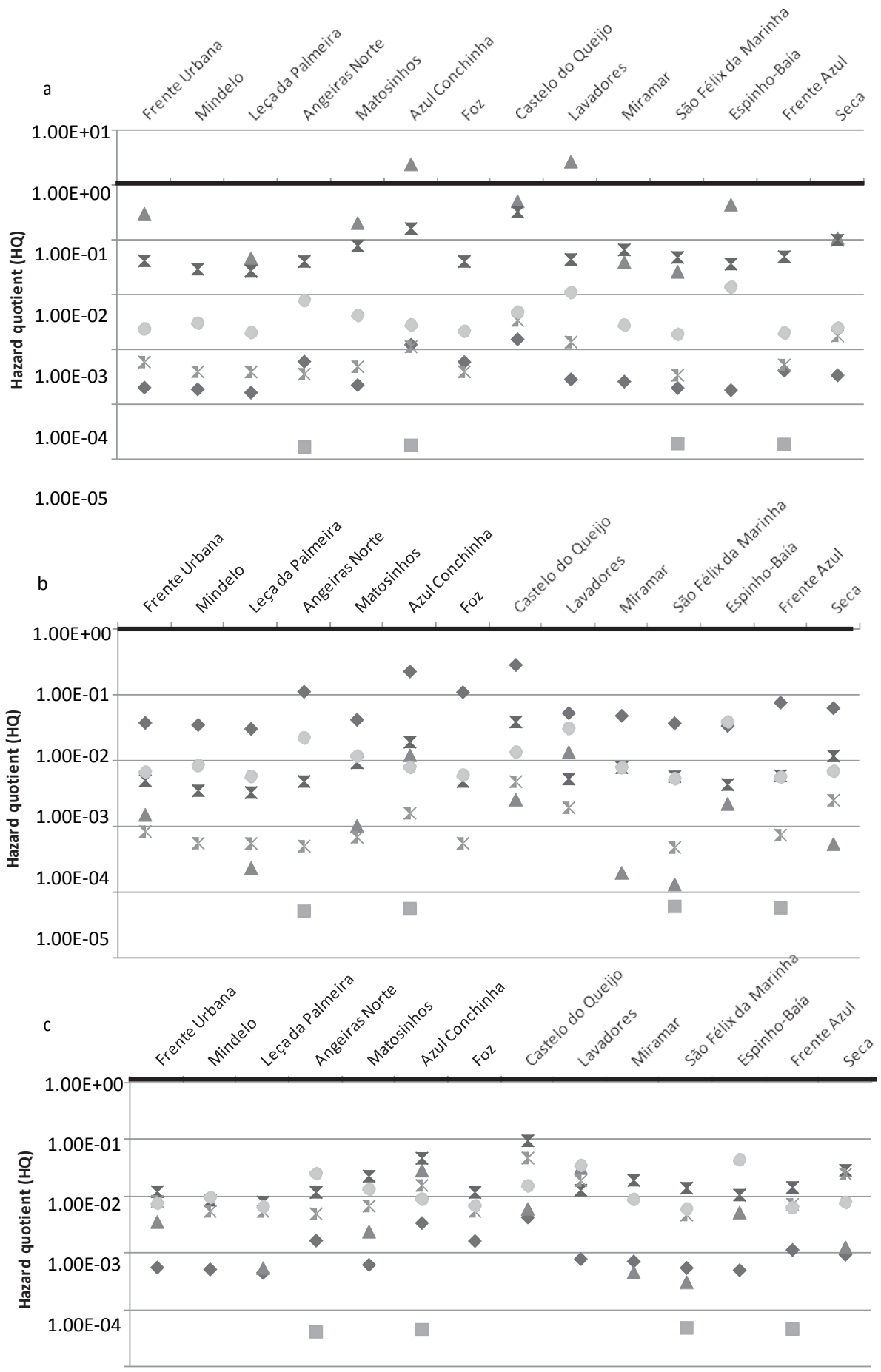

$1.00 \mathrm{E}-05$

-Acetaminophen $\square$ Acetylsalicylic acid $\Delta$ Diclofenac $\mathbf{Z}$ Ibuprofen $\mathbb{X}$ Naproxen Ketoprofen

Fig. 6. Hazard quotients of seawaters from different locations for three trophic levels. a) fish; b) daphnid; c) algae. Bold line marks hazard quotient equal to one. 
Lavadores (Vila Nova de Gaia)) it was higher than one (Fig. 6a). Ibupro- fen also showed high HQs for fish, although the threshold limit was never exceeded. For daphnids, the highest HQs were obtained for acet- aminophen (Fig. 6b), while algae showed similar sensitivity to the phar- maceuticals ketoprofen, ibuprofen and naproxen (Fig. 6c).

The results showed that diclofenac was the only pharmaceutical that might be expected to pose an ecotoxicological risk to fish. Furthermore, HQs higher than one were observed in seawaters classified as excellent bathing water (Lavadores beach (Vila Nova de Gaia)) (European Comission, 2006). These findings are evidence that legislation has to be updated in order to consider other parameters beyond microbiological ones, since emerging pollutants as pharmaceuticals have been detected in seawaters, sometimes at levels that can pose an ecotoxicological risk to non-target organisms. Additionally, diclofenac was recently included in a watch list to gather monitoring data of its occurrence in surface waters, including coastal and marine waters, as well as to assess its environmen- tal impact (European Comission, 2013). Contrarily to what happens in Portuguese seawaters, a $\mathrm{HQ}$ of 0.004 for diclofenac was reported in north- ern Taiwan seawaters (Fang et al., 2012).

The evaluation of environmental risk assessment followed herein only focused on the ecotoxicity that individual pharmaceuticals might pose to aquatic organisms. Nevertheless, pharmaceuticals occur in the environment as complex mixtures of different therapeutic groups, their metabolites and transformation products that may have synergis- tic or additive effects and, consequently, showing higher toxicities than individual compounds. In fact, combinatory effects were observed for different NSAIDs when analyzed as a mixture, having more toxicity than individual pharmaceuticals (Cleuvers, $2003,2004)$, as well as when in the presence of pharmaceuticals of other therapeutic groups (DeLorenzo and Fleming, 2008; Quinn et al., 2009).

\section{Conclusions}

The presence of NSAIDs and analgesic pharmaceuticals and metabo- lites was for the first time reported in Portuguese seawaters at concen- trations up to $1227 \mathrm{ng} \mathrm{L}^{-1}$. The highest concentrations for most of the pharmaceuticals found in seawaters were reported in Porto coastal area, showing that more densely populated areas have a high impact of anthropogenic activities. Seawaters with different bathing water quality classifications (excellent, good and sufficient) were studied and all the nine compounds were detected in at least one sample. Mul-

tivariate statistical analysis showed to have a positive correlation be- tween bathing waters classified as sufficient and a more pronounced impact of human activities. A temporal evaluation of their occurrence along bathing season showed that higher concentrations were reported in August and September months, which can be due to an increment of population in the study areas during the holidays. Environmental risk assessment posed by pharmaceuticals found in seawaters was also eval- uated, showing that only diclofenac had a HQ higher than one for fish and therefore may pose a risk for aquatic organisms.

The obtained data suggests that legislation should be updated in order to consider other parameters beyond microbiological ones in the classification of bathing water quality. In addition, more monitoring studies should be made in order to better understand the level of pollu- tion of marine environment and establish actions to prevent and reme- diate the introduction of emerging contaminants into seawaters.

\section{Acknowledgments}

This work received financial support from the European Regional Development Fund (ERDF) through the COMPETE - Operational Competitiveness Programme and national funds through FCT Foundation for Science and Technology, under the projects PEst-C/ EQB/LA0006/2013 and PEst-C/MAR/LA0015/2013.
Appendix A. Supplementary data

Supplementary data to this article can be found online at http://dx. doi.org/10.1016/j.scitotenv.2014.11.097.

\section{References}

APA. Portuguese Environment Agency. http://www.apambiente.pt/, 2013. (accessed in: 30th September 2013).

Araujo L, Troconis Maria E, Espina Maria B, Prieto Avismelsi. Persistence of ibuprofen, ketoprofen, diclofenac and clofibric acid in natural waters. J. Environ. Hum. 2014;1: 32-8.

Azur MJ, Stuart EA, Frangakis C, Leaf PJ. Multiple imputation by chained equations: what is it and how does it work? Int. J. Methods Psychiatr. Res. 2011;20:40-9.

Bay SM, Vidal-Dorsch DE, Schlenk D, Kelley KM, Maruya KA, Gully JR. Integrated coastal effects study: synthesis of findings. Environ. Toxicol. Chem. 2012;31:2711-22.

Bayen S, Zhang H, Desai MM, Ooi SK, Kelly BC. Occurrence and distribution of pharmaceu- tically active and endocrine disrupting compounds in Singapore's marine environ- ment: influence of hydrodynamics and physical-chemical properties. Environ. Pollut. 2013;182:1-8.

Cleuvers M. Aquatic ecotoxicity of pharmaceuticals including the assessment of combina- tion effects. Toxicol. Lett. 2003;142:185-94.

Cleuvers M. Mixture toxicity of the anti-inflammatory drugs diclofenac, ibuprofen, naproxen, and acetylsalicylic acid. Ecotoxicol. Environ. Saf. 2004;59:309-15.

DeLorenzo ME, Fleming J. Individual and mixture effects of selected pharmaceuticals and personal care products on the marine phytoplankton species Dunaliella tertiolecta. Arch. Environ. Contam. Toxicol. 2008;54:203-10.

European Comission. Technical guidance document on risk assessment in support of Commission Directive 93/67/EEC on risk assessment for new notified substances. Commission Regulation (EC) No 1488/94 on Risk Assessment for existing substances, and Directive 98/8/EC of the European Parliament and of the Council concerning the placing of biocidal products on the market. Part II. Italy: Institute for Health and Con- sumer Protection; 2003.

European Comission. Directive 2006/7/EC of the European Parliament and of the Council of 15 February 2006 concerning the management of bathing water quality and repealing Directive 76/160/EEC. In: Union E, editor. Off. J. Europ. Union, L64.; 2006. p. 37-51.

European Comission. Directive 2008/56/EC of the European Parliament and of the Council of 17 June 2008 establishing a framework for community action in the field of marine environmental policy (Marine Strategy Framework Directive). In: Union E, editor. Off. J. Europ. Union, L164.; 2008. p. 19-40.

European Comission. Directive 2013/39/EU of 12 August 2013 amending Directives 2000/60/EC and 2008/105/EC as regards priority substances in the field of water policy. Di- rective 2013/39/EU. Off. J. Europ. Union, L226; 2013. p. 1-17.

Fang T-H, Nan F-H, Chin T-S, Feng H-M. The occurrence and distribution of pharmaceuti- cal compounds in the effluents of a major sewage treatment plant in Northern Taiwan and the receiving coastal waters. Mar. Pollut. Bull. 2012;64:1435-44.

Farré $\mathrm{Ml}$, Pérez S, Kantiani L, Barceló D. Fate and toxicity of emerging pollutants, their me- tabolites and transformation products in the aquatic environment. TrAC Trends Anal. Chem. 2008;27:991-1007.

Ferrando-Climent L, Collado N, Buttiglieri G, Gros M, Rodriguez-Roda I, Rodriguez-Mozaz S, Barcelo D. Comprehensive study of ibuprofen and its metabolites in activated sludge batch experiments and aquatic environment. Sci. Total Environ. 2012;438: 404-13.

Ginebreda A, Muñoz I, López de Alda M, Brix R, López-Doval J, Barceló D. Environmental risk assessment of pharmaceuticals in rivers: relationships between hazard indexes and aquatic macroinvertebrate diversity indexes in the Llobregat River (NE Spain). Environ. Int. 2010;36:153-62.

Gonçalves CMO, Sousa MAD, Alpendurada MFPSPM. Analysis of acidic, basic 
and neutral pharmaceuticals in river waters: clean-up by 1 degrees, 2 degrees amino anion ex- change and enrichment using an hydrophilic adsorbent. Int. J. Environ. Anal. Chem. 2013;93:1-22.

Gros M, Petrovic M, Barceló D. Development of a multi-residue analytical methodology based on liquid chromatography-tandem mass spectrometry (LC-MS/MS) for screening and trace level determination of pharmaceuticals in surface and wastewa- ters. Talanta 2006;70:678-90.

Gros M, Rodríguez-Mozaz S, Barceló D. Fast and comprehensive multiresidue analysis of a broad range of human and veterinary pharmaceuticals and some of their metabo- lites in surface and treated waters by ultra-high-performance liquid chromatography coupled to quadrupole-linear ion trap tandem mass spectrometry. J. Chromatogr. A 2012;1248:104-21.

INE. Tourism Statistics 2013. www.ine.pt/, 2014. (accessed in 20th

November 2014). INFARMED. Estatística do Medicamento. INFARMED; 2012.

Kunkel U, Radke M. Fate of pharmaceuticals in rivers: deriving a benchmark dataset at fa- vorable attenuation conditions. Water Res. 2012;46:5551-65.

Loos R, Locoro G, Contini S. Occurrence of polar organic contaminants in the dissolved water phase of the Danube River and its major tributaries using SPE-LC-MS ${ }^{2}$ analysis. Water Res. 2010;44:2325-35.

Loos R, Carvalho R, Antonio DC, Cornero S, Locoro G, Tavazzi S, Paracchini B, Ghiani M, Lettieri T, Blaha L, Jarosova B, Voorspoels S, Servaes K, Haglund P, Fick J, Lindberg RH, Schwesig D, Gawlik BM. EU-wide monitoring survey on emerging polar organic contaminants in wastewater treatment plant effluents. Water Res. 2013a;47: 6475-87. 
Loos R, Tavazzi S, Paracchini B, Canuti E, Weissteiner C. Analysis of polar organic contam- inants in surface water of the northern Adriatic Sea by solid-phase extraction follow- ed by ultrahigh-pressure liquid chromatography-QTRAP(A (R)) MS using a hybrid triple-quadrupole linear ion trap instrument. Anal. Bioanal. Chem. 2013b;405: 587585.

Madureira TV, Barreiro JC, Rocha MJ, Rocha E, Cass QB, Tiritan ME. Spatiotemporal distri- bution of pharmaceuticals in the Douro River estuary (Portugal). Sci. Total Environ. 2010;408:5513-20.

Navarro A, Tauler R, Lacorte S, Barcelo D. Occurrence and transport of pesticides and alkylphenols in water samples along the Ebro River Basin. J. Hydrol. 2010;383:18-29. Nebot C, Gibb SW, Boyd KG. Quantification of human pharmaceuticals in water samples by high performance liquid Chim. Acta. 2007;598:87-94. chromatography-tandem mass spectrometry. Anal.

Nödler K, Licha T, Bester K, Sauter M. Development of a multi-residue analytical method, based on liquid chromatography-tandem mass spectrometry, for the simultaneous determination of 46 microcontaminants in aqueous samples. J. Chromatogr. A 2010;1217:6511-21.

Paíga P, Santos LMLM, Amorim C, Araújo A, Montenegro MCSM, Pena A, Delerue-Matos C. Pilot monitoring study of ibuprofen in surface waters of north of Portugal. Environ. Sci. Pollut. Res. 2013;20:2410-20.

Paíga P, Lolić A, Hellebuyck F, Santos LHMLM, Correia M, Delerue-Matos C. Development

of a SPE-UHPLC-MS/MS methodology for the determination of nonsteroidal anti- inflammatory and analgesic pharmaceuticals in seawater. J. Pharm. Biomed. Anal. 2014. http://dx.doi.org/10.1016/j.jpba.2014.06.017. (in press).

Quinn B, Gagné F, Blaise C. Evaluation of the acute, chronic and teratogenic effects of a mixture of eleven pharmaceuticals on the cnidarian, Hydra attenuata. Sci. Total Envi- ron. 2009;407:1072-9.

Rabiet M, Togola A, Brissaud F, Seidel JL, Budzinski H, Elbaz-Poulichet F. Consequences of treated water recycling as regards pharmaceuticals and drugs in surface and ground waters of a medium-sized Mediterranean catchment. Environ. Sci. Technol. 2006;40: 5282-8.

Ribeiro C, Tiritan M, Rocha E, Rocha M. Seasonal and spatial distribution of several endocrine-disrupting compounds in the Douro River Estuary, Portugal. Arch. Environ. Contam. Toxicol. 2009;56:1-11.

Rocha MJ, Ribeiro M, Ribeiro C, Couto C, Cruzeiro C, Rocha E. Endocrine disruptors in the Leça River and nearby Porto Coast (NW Portugal): presence of estrogenic compounds and hypoxic conditions. Toxicol. Environ. Chem. 2012;94:262-74.

Rocha MJ, Cruzeiro C, Rocha E. Quantification of 17 endocrine disruptor compounds and their spatial and seasonal distribution in the Iberian Ave River and its coastline. Toxicol. Environ. Chem. 2013;95:386-99.

Rodriguez-Navas C, Bjoerklund E, Bak SA, Hansen M, Krogh KA, Maya F, Forteza

$R$, Cerda

V. Pollution pathways of pharmaceutical residues in the aquatic environment on the Island of Mallorca, Spain. Arch. Environ. Contam. Toxicol. 2013;65:56-66.
Santos LHMLM, Gros M, Rodriguez-Mozaz S, Delerue-Matos C, Pena A, Barceló D, Montenegro MCBSM. Contribution of hospital effluents to the load of pharmaceuti- cals in urban wastewaters: identification of ecologically relevant pharmaceuticals. Sci. Total Environ. 2013a;461462:302-16.

Santos LHMLM, Paíga P, Araújo AN, Pena A, Delerue-Matos C, Montenegro MCBSM. Devel- opment of a simple analytical method for the simultaneous determination of paracet- amol, paracetamol-glucuronide and p-aminophenol in river water. J. Chromatogr. B 2013b;930:75-81.

Shanmugam G, Sampath S, Selvaraj KK, Larsson DGJ, Ramaswamy BR. Nonsteroidal anti- inflammatory drugs in Indian rivers. Environ. Sci. Pollut. Res. 2014;21:921-31.

Straub JO. Environmental risk assessment for new human pharmaceuticals in the European Union according to the draft guideline/discussion paper of January 2001. Toxicol. Lett. 2002;131:137-43.

Togola A, Budzinski H. Multi-residue analysis of pharmaceutical compounds in aqueous samples. J. Chromatogr. A 2008;1177:150-8.

Verlicchi P, Al Aukidy M, Zambello E. Occurrence of pharmaceutical compounds in urban wastewater: removal, mass load and environmental risk after a secondary treatment - a review. Sci. Total Environ. 2012;429:123-55.

Vidal-Dorsch DE, Bay SM, Maruya K, Snyder SA, Trenholm RA, Vanderford BJ. Contami- nants of emerging concern in municipal wastewater effluents and marine receiving water. Environ. Toxicol. Chem. 2012;31:2674-82.

Weigel S, Kuhlmann J, Hühnerfuss H. Drugs and personal care products as ubiquitous pollutants: occurrence and distribution of clofibric acid, caffeine and DEET in the North Sea. Sci. Total Environ. 2002;295:13141.

Weigel S, Berger $U$, Jensen $E$, Kallenborn R, Thoresen $H$, Hühnerfuss $H$. Determination of selected pharmaceuticals and caffeine in sewage and seawater from Troms $\varnothing /$ Norway with emphasis on ibuprofen and its metabolites. Chemosphere 2004;56: 583-92.

Wille K, Noppe H, Verheyden K, Vanden Bussche J, De Wulf E, Van Caeter P, Janssen CR, De Brabander HF, Vanhaecke L. Validation and application of an LC-MS/MS method for the simultaneous quantification of 13 pharmaceuticals in seawater. Anal. Bioanal. Chem. 2010;397:1797808.

Winkler M, Lawrence JR, Neu TR. Selective degradation of ibuprofen and clofibric acid in two model river biofilm systems. Water Res. 2001;35:3197-205.

Wu J, Qian X, Yang Z, Zhang L. Study on the matrix effect in the determination of selected pharmaceutical residues in seawater by solid-phase extraction and ultra-high- performance liquid chromatography-electrospray ionization low-energy collision- induced dissociation tandem mass spectrometry. J. Chromatogr. A 2010;1217: 1471-5.

Ziylan A, Ince NH. The occurrence and fate of anti-inflammatory and analgesic pharmaceu- ticals in sewage and fresh water: treatability by conventional and non-conventional processes. J. Hazard. Mater. 2011;187:24-36. 